\title{
Espectrometria de Massa na Análise de Sistemas Biológicos
} Inês C. Santos

\begin{abstract}
Mass Spectrometry to Study Biological Systems. The need for high-throughput techniques for the analysis of biomolecules such as proteins and nucleic acids in biological experiments is currently critical to know its structure, function, and interactions. Mass spectrometry can be used to complement traditional techniques in the study of biological systems and provide a more complete understanding of the biological processes under examination. Native mass spectrometry has shown to be a critical tool to analyse proteins, protein complexes, and nucleic acids. These methods are used to study alterations in the structure of these biomolecules, identify the presence of mutations/modifications, and identify binding site motifs to answer questions related to human health and drug development. The use of mass spectrometry coupled to ultraviolet photodissociation for the analysis of proteins and nucleic acids are emphasized in this article.
\end{abstract}

\begin{abstract}
O estudo de biomoléculas, mais concretamente da sua sequência, estrutura e tipo de interações em que estão envolvidas, é importante para compreender a sua função e a sua relação com diferentes doenças. A espectrometria de massa tem provado ser uma metodologia complementar às abordagens tradicionais para o estudo dos sistemas biológicos e que ajuda a aprofundar a sua compreensão. Neste artigo, é apresentada uma revisão do uso de espectrometria de massa acoplada à fotoionização por raios ultravioleta para a análise de proteínas e ácidos nucleicos. Estes métodos são utilizados para estudar alterações na estrutura destas biomoléculas, identificar a presença de modificações e identificar locais de interação com outras moléculas de forma a responder a questões relacionadas com a saúde humana e o desenvolvimento de fármacos.
\end{abstract}

\section{Introdução}

O papel dos ácidos nucleicos é reter toda a informação genética, estando também envolvidos na sua tradução em proteínas que, por sua vez, contribuem para a função e estrutura das células. Por conseguinte, as proteínas têm sido alvo de vários estudos direcionados para o desenvolvimento de fármacos [1,2]. Estas biomoléculas constituem alvos ideais visto que interagem com diferentes tipos de moléculas e estas interações têm impacto na sua conformação, atividade e, consequentemente, na função que desempenham podendo levar à perda ou redução da sua atividade biológica. Por estas razões, é importante conhecer, para cada proteína, não só a sequência de aminoácidos na sua cadeia polipeptídica e a sua estrutura tridimensional, mas também as moléculas com que interage e com que tipo de interações [1-3].

A cristalografia de raios-X e a espectroscopia de ressonância magnética nuclear (RMN) são as técnicas mais utilizadas no estudo da estrutura tridimensional de proteínas [4,5]. Contudo, as moléculas com elevada massa molecular não cristalizam facilmente, o que dificulta o estudo da sua estrutura por cristalografia. A crio-microscopia eletrónica (Cryo-EM) ultrapassa 
esta limitação. No entanto, esta técnica possui uma baixa resolução, isto é, uma menor capacidade para determinar os detalhes estruturais. Por outro lado, a RMN, além de apresentar a mesma limitação, requer uma grande quantidade de amostra pura, na ordem dos mg, para obter espectros de qualidade [4-8]. Assim, são necessários métodos alternativos para a caracterização das biomoléculas. A espectrometria de massa é uma excelente técnica que complementa as mencionadas anteriormente na identificação e caracterização de proteínas, nomeadamente através da determinação da sequência primária, localização de modificações pós-traducionais, identificando os resíduos em que se encontra a alteração, contribuindo também para a determinação da sua estrutura tridimensional e a sua quantificação [9-17].

\section{Espectrometria de massa}

J. J. Thompson, em 1912, demonstrou que era possível separar moléculas na fase gasosa através das diferenças de massa e carga que estas apresentam, o que corresponde ao princípio de funcionamento dos espectrómetros de massa [18]. A espectrometria de massa (EM) permite a análise qualitativa e quantitativa de átomos ou moléculas com base na relação entre a massa e a carga de espécies ionizadas em fase gasosa [19]. Os principais componentes de um espectrómetro de massa estão representados na Figura 1. Estes incluem uma fonte de ionização para promover a ionização dos analitos, um analisador de massa, que separa os iões formados e um detetor [19]. As fontes de ionização utilizadas mais frequentemente são ionização química (Chemical lonization, Cl), ionização por spray eletrostático (Electrospray lonization, ESI) e ionização por dessorção laser assistida por matriz (Matrix Assisted Laser Desorption/Ionization, MALDI) $[19,20]$. O desenvolvimento da técnica de ionização por spray eletrostático por John Fenn foi um grande marco na análise de biomoléculas visto que permitiu evaporar e ionizar macromoléculas, causando uma fragmentação mínima das ligacções químicas [21,22]. A partir dessa altura, o uso de espectrometria de massa passou a ser alargado ao estudo de macromoléculas biológicas como péptidos, proteínas, polissacarídeos e ácidos nucleicos. Na técnica de ESI, a amostra passa por um capilar no qual se aplica um elevado potencial elétrico (3-5 kV). Na saída do capilar, a solução dispersa-se na forma de microgotículas eletricamente carregadas. O seu volume é rapidamente reduzido por evaporação do solvente criando, usualmente por protonação, iões na fase gasosa [21,22]. No caso das proteínas, os locais de protonação mais frequentes são o N-terminal e os resíduos histidina, arginina e lisina. Os iões individualizados são separados com base na sua massa $(m)$ e carga $(z)$, mais exatamente na razão $\mathrm{m} / \mathrm{z}$. Os analisadores divergem no modo de aceleração e separação de iões e as suas principais características são o limite de massa, o modo de transmissão de iões e a resolução de massa. Os diferentes tipos de analisadores são quadrupolos (Q), armadilha de iões (ion-traps), tempo de voo (Time of Flight, TOF), Orbitrap ${ }^{\mathrm{TM}}$ e ressonância ião-ciclotrão com transformada de Fourier (FTICR) $[23,24]$. No TOF, os iões são acelerados por um potencial entre dois elétrodos e transferidos para um tubo em alto vácuo em que as suas velocidades são inversamente proporcionais às suas massas. A relação entre a massa e a carga é determinada pelo tempo de voo entre a ionização e a deteção. 0 detetor converte o sinal dos iões para um sinal analógico que é apresentado como um gráfico de intensidade versus $\mathrm{m} / \mathrm{z}$, referido como o espectro de massa. Os analisadores quadrupolo são constituídos por quatro elétrodos que funcionam como um filtro. 0 campo elétrico formado entre esses elétrodos permite selecionar os iões incluídos num intervalo $\mathrm{m} / \mathrm{z}$ que são enviados para o detetor, enquanto os outros são desviados. Os analisadores de armadilha de iões filtram e capturam os iões de interesse, que são libertados gradualmente por ordem crescente de $m / z$. No analisador Orbitrap ${ }^{\mathrm{TM}}$, os iões oscilam ao longo e ao redor de um elétrodo em forma de espiral. A frequência dessa oscilação é proporcional à raiz quadrada da razão $\mathrm{m} / \mathrm{z}$ permitindo a sua determinação com elevada exatidão.

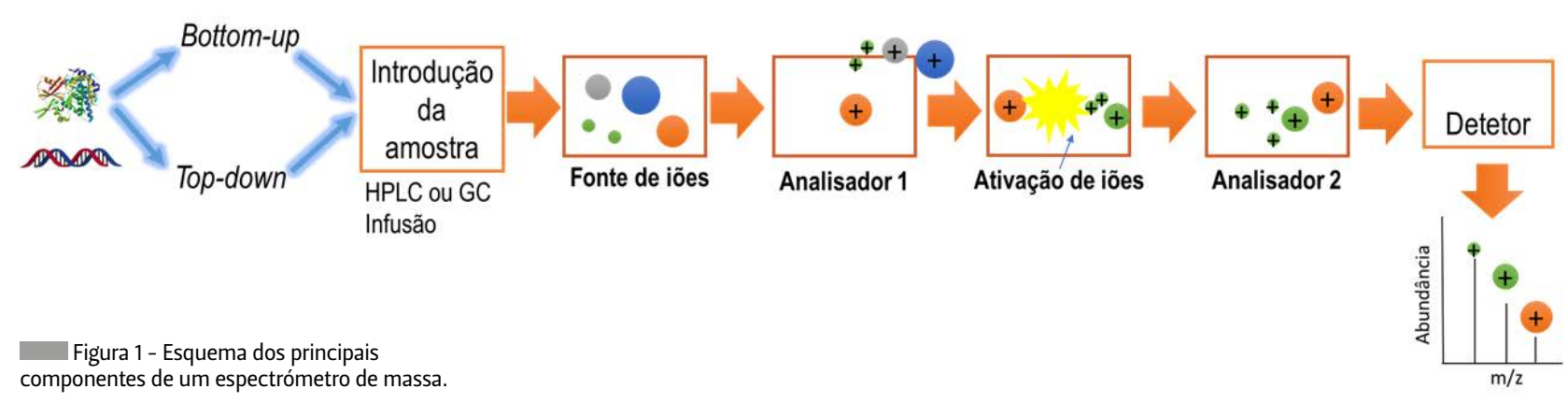


A Colisão com um gás inerte
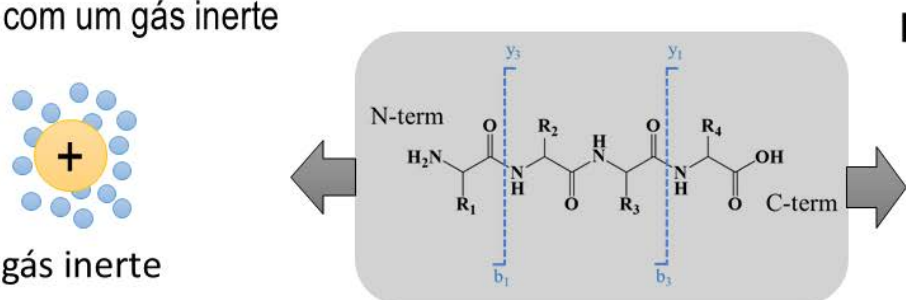

D Colisão com uma superfície

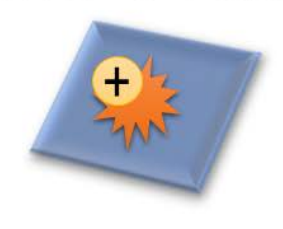

E Dissociação por captura de eletrões de eletrões

$e^{-}$
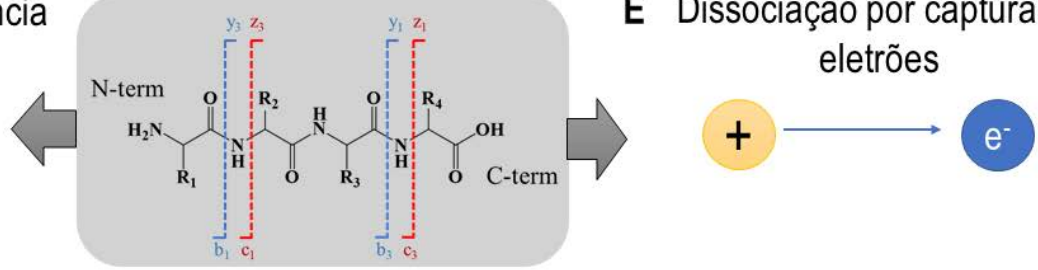

Figura 2 - Tipos de ativação possíveis em espectrometria de massa e respetivos iões produzidos.

\subsection{Espectrometria de massa tandem}

A espectrometria de massa tandem (MS/MS) permite a clivagem de iões em fragmentos com o objetivo principal de definir a sequência de aminoácidos das proteínas. Existem diferentes modos de ativação de iões, detalhados na Figura 2, incluindo colisão com um gás inerte (collision induced dissociation, CID, Fiğ. 2A), dissociação por transferência de eletrões (electron transfer dissociation, ETD, Fig. 2B), fotodissociação por raios infravermelhos (infrared multiple photon dissociation, IRMPD) ou ultravioleta (ultraviolet photodissociation, UVPD, Fig. 2C), colisão com uma superfície (surface induced dissociation, SID, Fig. 2D) e captura eletrónica (electron capture dissocation, ECD, Fig. 2E) [25].

O CID é a forma mais comum de ativação devido à sua simplicidade e elevada eficiência de fragmentação. Consequentemente, esta técnica tem sido implementada na generalidade dos espectrómetros de massa. Este processo de ativação tem origem em colisões promovidas entre iões dos analitos e átomos ou moléculas de um gás inerte que promovem a conversão da energia cinética em energia interna, causando a fragmentação de ligações químicas [26]. A fragmentação de ligações covalentes fracas, como as ligaç̧ões $\mathrm{C}-\mathrm{N}$ dos péptidos, é proeminente em métodos de ativação de baixa energia, tais como CID e IRMPD, resultando na formação de iões do tipo b e y como apresentado na Figura $2 A[26,27]$. Consequentemente, são também comuns a perda de $\mathrm{NH}_{3}$ ou $\mathrm{H}_{2} \mathrm{O}$ de iões $b / y$, bem como a perda de $\mathrm{CO}$ de iões do tipo $b$ para a produção de iões do tipo $a$.

A SID permite uma deposição rápida de alta energia que introduz novas vias de fragmentação não acessíveis com processos mais lentos e menos energéticos como o CID [28]. Este método já foi implementado numa grande variedade de espectrómetros de massa, abrangendo os que incluem analisadores de massa Q-TOF, Orbitrap ${ }^{T M}$ e FTICR [29]. Este tipo de ativação é também conhecido pela produção de iões do tipo b/y e, comparativamente com o CID, permite ainda a caracterização da estrutura quaternária de complexos proteicos.

As técnicas de ativação baseadas em transferência de eletrões, incluindo ECD e ETD, preservam ligações não covalentes e geram iões cuja abundância reflete a flexibilidade da proteína. Estas técnicas promovem a fragmentação das ligaç̧ões $\mathrm{N}-\mathrm{C} \alpha$ que resultam na produção de iões do tipo $\mathrm{c} / z$ [30].

Os métodos de ativação que resultam numa maior deposição energética permitem o acesso a uma maior variedade de processos de fragmentação. Por exemplo, a UVPD gera iões do tipo a/ $x$ através da fragmentação de ligáções $C \alpha-C$, além de iões $b / y$ e $c / z$. Em geral, os iões $a / x, b / y$ e $c / z$ são os mais úteis para identificar a sequência primária de um péptido ou proteína [31-39].

Na Figura 3 é possível ver um exemplo da introdução de um laser na zona posterior de um espectrómetro de massa para realizar a fotodis- 
sociação por raios ultravioleta. A UVPD pode ser implementada em quadrupolos, armadilha de iões ou na célula de dissociação colisional de alta energia (high energy collision dissociation, HCD). A utilização de fotodissociação requer uma fonte de fotões adequada, um meio de introdução destes fotões no espectrómetro de massa, tais como uma janela e lentes e/ou espelhos que direcionam os fotões, e um método que permite desencadear a dissociação ao mesmo tempo que os iões são analisados, isto é, quando os iões são aprisionados, estes são também ativados por UVPD. As fontes de fotões utilizadas com sucesso para a fotodissociação foram descritas previamente em artigos de revisão [31-39] e incluem lasers de $\mathrm{CO}_{2}$, lasers excimer, lasers de estado sólido Nd:YAG, entre outros.

Figura 3 - Instalação de UVPD num espectrómetro de massa Thermo Fisher Scientific Orbitrap Lumos. Adaptada com permissão da referência [32]. Copyright 2020 American Chemical Society.

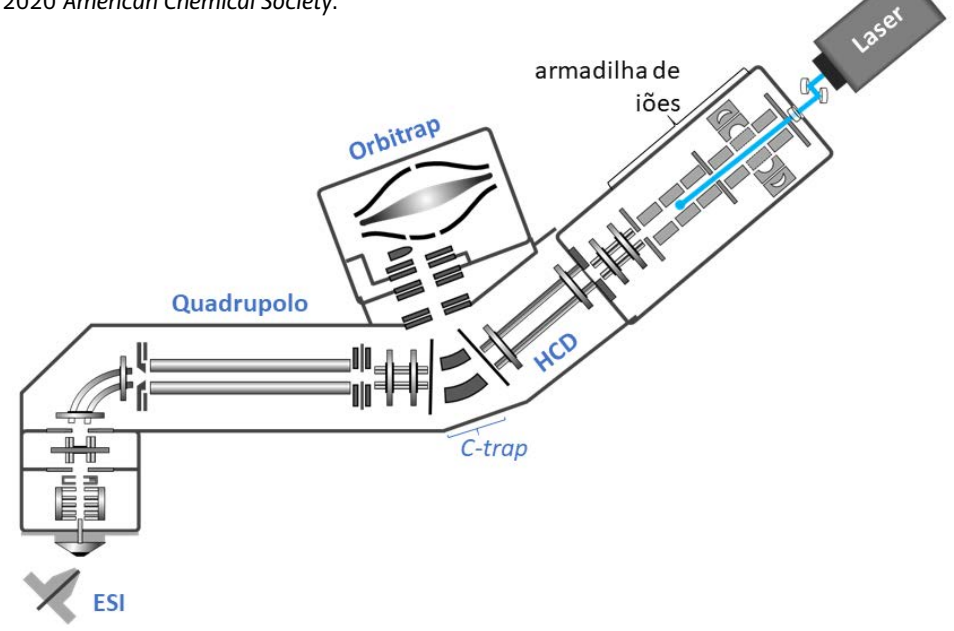

Alguns dos tipos de fragimentação já referidos apresentam desvantagens, tais como a baixa produção de fragmentos e a perda de modificações que conduzem a uma baixa cobertura da sequência de proteínas e ácidos nucleicos. Para contornar esta limitação, diferentes métodos de ativação podem ser combinados num único passo ou em passos sequenciais de forma a combinar as vantagens das diferentes técnicas para uma melhor caracterização de proteínas e ácidos nucleicos [31,32]. Um exemplo é a ativação por UVPD seguida por ativação por CID explicada em mais pormenor na secção 3.3.

\section{Espectrometria de massa aplicada a sistemas biológicos}

A análise de proteínas por espectrometria de massa pode ser realizada de duas formas: bottom-up ou top-down [40-45]. No primeiro método, as proteínas são digeridas a péptidos por proteases específicas como a tripsina. Antes da análise por espectrometria de massa, os péptidos são separados por cromatografia líquida de forma a evitar supressões de sinal [40-43]. A análise de péptidos é indiscutivelmente mais simples comparativamente à análise de proteínas intactas tanto em termos de separação por cromatografia ou eletroforese como na produção de espectros mais fáceis de interpretar. Por esta razão, este método permite a identificação da proteína através da determinação da sua sequência, complementada com a razão $\mathrm{m} / \mathrm{z}$ determinada para os péptidos trípticos. Além disso, é possível identificar a presença de modificações pós-traducionais (post-translational modifications, PTMs) de aminoácidos resultantes de uma modificação química. Contudo, uma das desvantagens reconhecidas da análise baseada em péptidos é a produção de péptidos excessivamente curtos que não permitem a identificação da proteína nem a identificação dos múltiplos locais que contêm modificações que podem ser críticas para a função das proteínas ou que estão relacionadas com certas doenças. Por esta razão, o método de top-down tem vindo a ser mais explorado de forma a obter maior cobertura da sequência da proteína e localizar os múltiplos grupos modificados. Neste método, as proteínas são analisadas intactas sem qualquer digestão [44,45]. A fragmentação de proteínas com certos métodos de ativação tais como UVPD permite a produção de fragmentos que contêm as modificações. Desta forma, a identificação dos péptidos produzidos e a identificação da massa correspondente a determinados grupos químicos permite identificar a sequência da proteína e mapear a presença de modificações. Na identificação de proteínas, o valor da massa dos diferentes fragmentos obtidos é comparado com a massa dos péptidos obtidos por digestão da proteína com uma protease específica, usualmente a tripsina, através do uso de motores de busca de dados como o SEQUEST [46], MASCOT [47], Andromeda ${ }^{\text {TM }}$ [48], Byonic ${ }^{\text {TM }}$ [49], MS Amanda $^{\mathrm{TM}}[50]$, entre outros.

Normalmente, a análise de proteínas por top-down utiliza soluções que desnaturam por completo a biomolécula para facilitar a sua fragimentação, como por exemplo uma mistura 50:50 água/acetonitrilo com $0,1 \%$ de ácido fórmico. Contudo, foi também demonstrado que as proteínas podem ser estudadas no seu estado nativo com a adição de acetato de amónio à solução onde estas são preparadas [51,52]. 0 estudo de proteínas no seu estado nativo é uma representação mais fiel do seu estado em sistemas biológicos e permite um estudo mais correto da sua estrutura e interação com outras moléculas, um ponto crítico no desenvolvimento de fármacos. 
3.1. Estudo de complexos proteína-ligando

O estudo de complexos proteína-ligando é um dos grandes focos no desenvolvimento de novos fármacos que interagem com proteínas e interferem na sua função. A identificação de alterações na estrutura tridimensional e na função das proteínas que ocorrem após interação com outras moléculas permite compreender o impacto destes ligandos na função biológica das proteínas. Vários métodos foram desenvolvidos para caracterizar as estruturas de complexos de proteínas com ligandos, tais como, a reorganização conformacional destas proteínas após ligação, os locais de ligação e as respetivas afinidades de ligação $[53,54]$. Recentemente, o desenvolvimento do nano spray eletrostático (similar ao spray eletrostático, mas com fluxos menores que formam gotículas mais pequenas) e o uso de soluções com elevada força iónica permitiram manter as interações não covalentes no estado gasoso e, consequentemente, 0 seu estudo através de espectrometria de massa [915,55-58]. Além disso, combinando a espectrometria de massa de proteínas nativas com espectrometria de massa tandem (MS/MS) é possível caracterizar a estrutura tridimensional da proteína e identificar o local onde esta interatua com o ligando $[53,54]$. Esta estratégia experimental aplica-se a variados tipos de ligandos, tais como moléculas pequenas, péptidos, lípidos ou ácidos nucleicos.

Vários métodos de ativação têm sido utilizados no estudo de complexos entre proteínas e os seus ligandos [36,37]. A técnica CID causa maioritariamente a dissociação destes complexos com a perda do ligando e a desnaturação da proteína e, por isso, esta técnica não permite o estudo da estrutura destes complexos [36,37]. Por outro lado, a ativação por fotoionização que utiliza fotões de alta energia (193 nm) mostrou ser uma ferramenta valiosa para estudos estruturais [59-68]. Esta técnica não só fornece uma extensa fragmentação da proteína, como gera fragmentos que mantêm a interação com os ligandos visto que este processo ocorre de forma mais rápida e com maior deposição de energia comparativamente à ativação por CID. Desse modo, são formados fragmentos que contêm o ligando ligado não covalentemente (iões holo) tal como fragmentos apenas de proteína (iões apo). Estes iões formam um padrão complementar que indica o local de interação entre a proteína e o ligando como demonstrado para a mioglobina na Figura 4 [59]. Além disso, as diferenças nos padrões de fragmentação podem ser usadas para rastrear alterações estruturais devido à ligação destes ligandos $[60,61,63-66,68]$. Num estudo, foi utilizada a UVPD (193 nm) para examinar alterações estruturais da mioglobina e das subunidades da hemoglobina após ligaç̧ão do grupo hemo [60]. De facto, em várias publicações $[60,61,63-66,68]$ foi reportado que as zonas em que a proteína interage com outras moléculas sofrem uma diminuição na quantidade de fragmentos gerados comparativamente com os observados na proteína isolada, sugerindo possíveis mudanças conformacionais após ligação com os ligandos. Este efeito é demonstrado na Figura 5 em que diferenças na fragmentação por UVPD ocorrem devido a alterações conformacionais da proteína anidrase carbónica após interação com um inibidor [69]. Zonas onde se encontram os resíduos que interagem com o ligando produziram menor quantidade de fragmentos. A maior quantidade de fragmentos produzidos nos restantes locais foi atribuída a uma maior flexibilidade nestas zonas visto não estarem envolvidas na interação com o ligando.

\subsection{Estudo de macrocomplexos de proteínas}

Outro objetivo importante deste tipo de estudos é a contribuição para a determinação da estrutura tridimensional de complexos de proteínas, que permitem a correlação com a sua função biológica. Cada proteína tem uma estrutura tridimensional única e pequenas mudanças estruturais podem levar a alterações da sua atividade biológica, em particular à sua perda. Recentemente, o desenvolvimento de novos espectrómetros de massa tem permitido a análise de macrocomplexos de proteínas, como sistemas CRISPR (do inglês Clustered Regularly Interspaced Short Palindromic Repeats), ribossomas e vírus com massas até 20 MDa [70-74]. A análise da massa/carga pode fornecer informações sobre a estequiometria visto que o aumento da massa permite identificar o número de ligandos presentes e topologia dos complexos de proteínas multiméricas, enquanto a distribuição do número de cargas indica a forma geral (cargas elevadas indicam estado desnaturado e cargas baixas indicam estado nativo) [70]. Dessa forma, a dissociação destes complexos permite uma melhor compreensão da sua composição e arquitetura [14,75-79]. Até ao momento, várias técnicas de ativação foram utilizadas para a caracterização de complexos macromoleculares com massa superior a $100 \mathrm{kDa}$, incluindo CID, ETD, ECD, SID e UVPD [14].

A ativação CID de proteínas no estado nativo provoca a ejeção de um monómero de cada vez em estado desnaturado, independentemente do tamanho e composição da proteína $[78,80,81]$. Esta dissociação assimétrica fornece informações estruturais limitadas, uma vez que o monómero desnaturado não retém informações topológicas. No entanto, podem ser obtidas informações sobre a estequiometria do complexo, como demonstrado em inúmeros estudos em que a ativação induzida por colisão foi utilizada para caracterizar ribossomas 


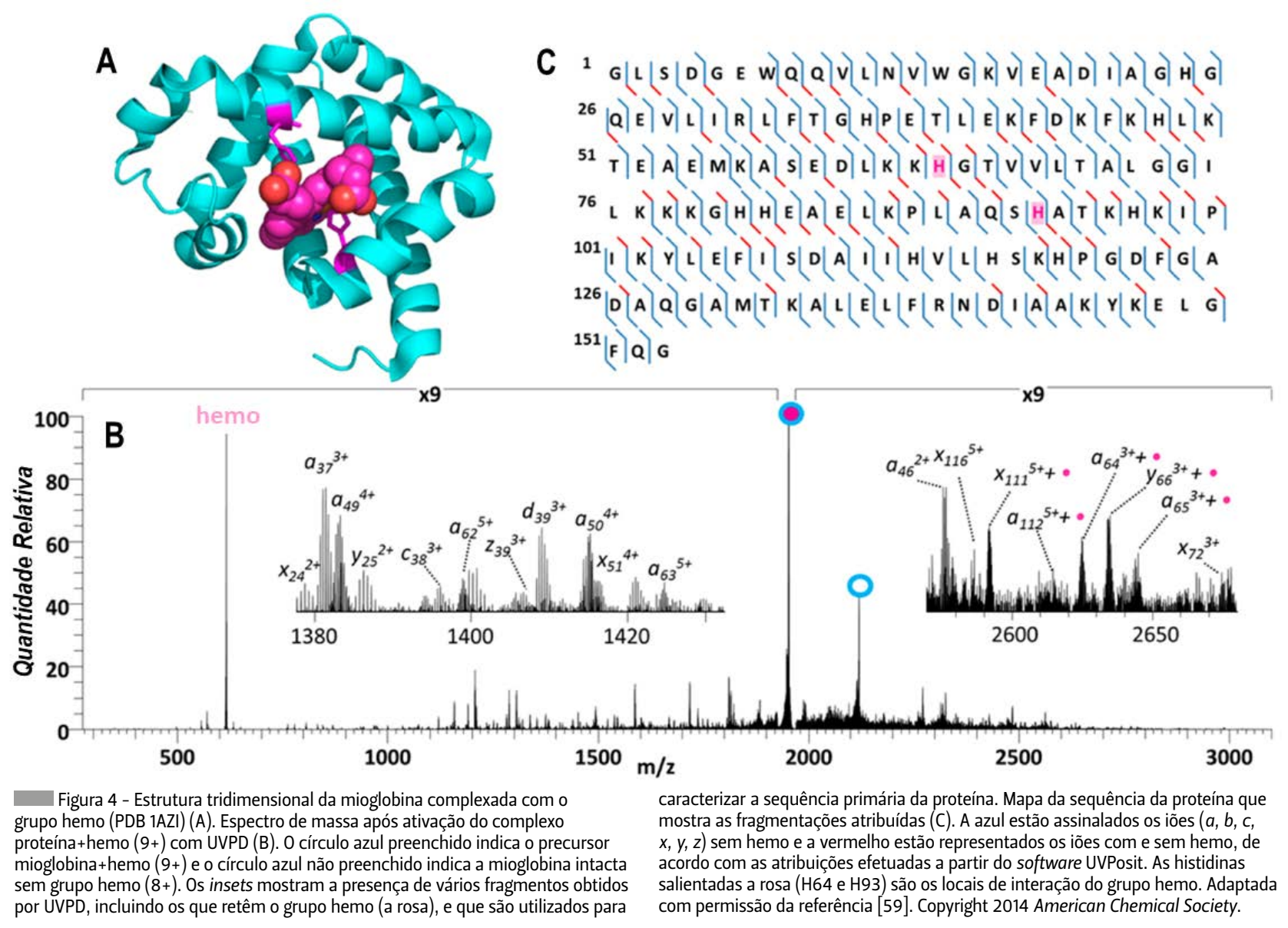

A
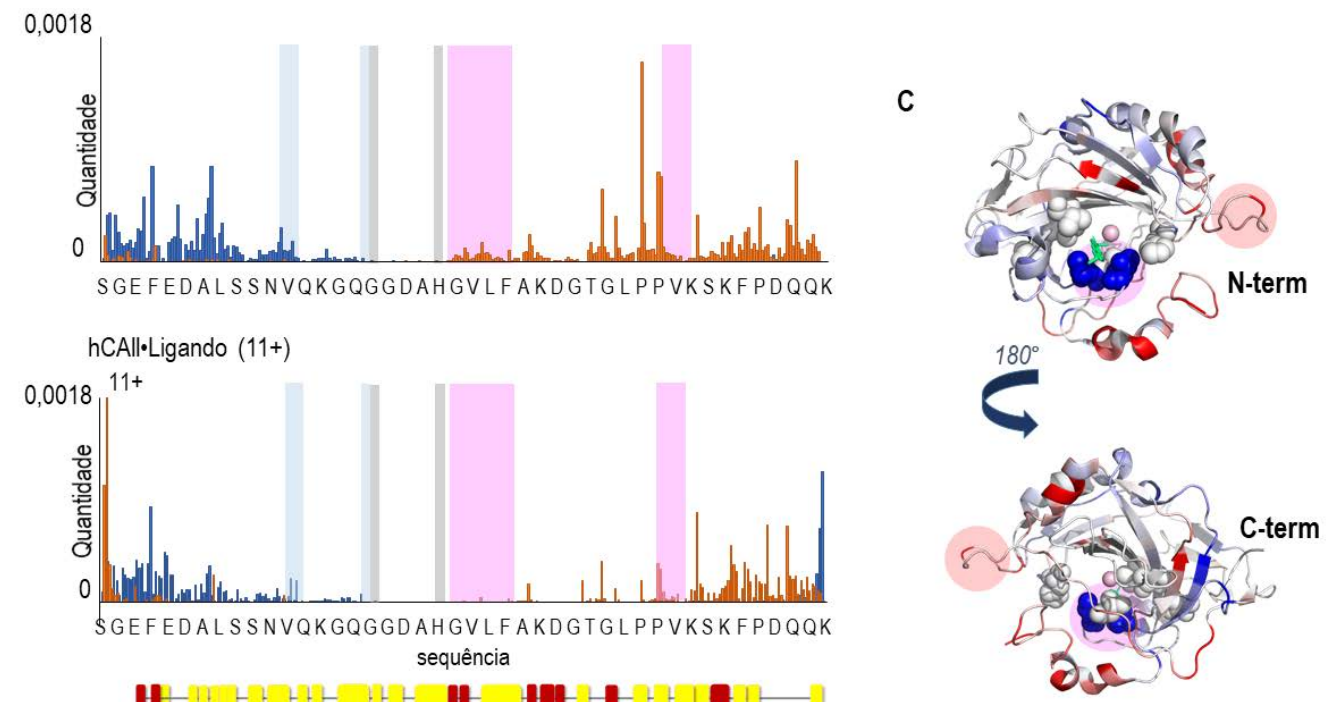

B

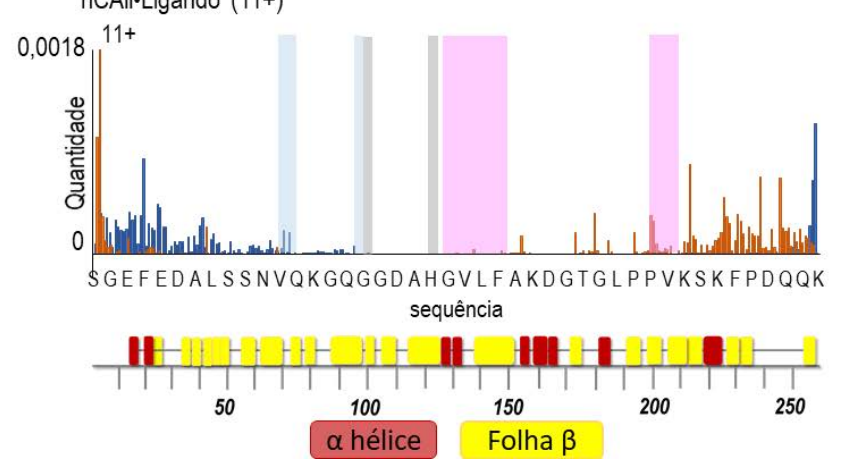

supressão aumento

Figura 5 - Abundância de fragmentos holo e apo produzidos após ativação com UVPD (A) da proteína anidrase carbónica (11+) e (B) do complexo desta proteína com o ligando etoxzolamida (11+). A sombreado estão representados os resíduos envolvidos na interação com o ligando, bolso hidrofóbico (rosa), bolso hidrofílico (azul) e resíduos que interagem com zinco (cinzento). As zonas onde a fragmentação foi suprimida estão representadas na estrutura da proteína (C) a azul e as zonas onde a fragmentação aumentou estão representadas a vermelho. No gráfico em baixo estão representadas as $\alpha$-hélice e folha- $\beta$ ao longo da sequência da proteína. Adaptada com permissão da referência [69]. Copyright 2021 American Chemical Society. 
intactos, determinando as massas do complexo e as das suas subunidades (50S e 305 para organismos procarióticos ou 605 e 405 para organismos eucarióticos), e identificando as proteínas que as constituem [82-88]. A ativação por transferência de eletrões (ETD e ECD) é também incapaz de provocar a ejeção de monómeros [89-92]. Por essa razão, estas técnicas não fornecem informações sobre a estrutura quaternária. Contudo, a ETD e a ECD levam à fragmentação das regiões proteicas mais expostas, o que permite um melhor conhecimento da flexibilidade da proteína.

A SID, tal como a UVPD, sendo técnicas de dissociação rápida e de alta energia, provocam a dissociação simétrica dos complexos proteicos com a ejeção de subunidades compactas e a formação de subcomplexos que mantêm um grau significativo de estrutura terciária [93-97]. Dessa forma, pode ser obtida informação sobre a estrutura quaternária dos complexos, como demonstrado para o proteassoma $20 S$ onde a SID foi utilizada para ativar o complexo e caracterizar os subcomplexos gerados [97]. Apesar de ser possível estudar a estrutura de complexos com SID, esta técnica produz um baixo número de fragmentos, o que torna difícil identificar e caracterizar os monómeros e subcomplexos produzidos. A UVPD, por outro lado, não só causa uma dissociação mais simétrica através da ejeção de monómeros em estado nativo como produz um maior número de fragmentos, permitindo caracterizar os monómeros e subcomplexos produzidos [67,98-100]. Recente- mente, a UVPD foi usada para caracterizar complexos macromoleculares como o complexo $\alpha 6 \beta 6 \gamma$ de 265 kDa, o sistema CRISPR-Cas Csy de 347 kDa e uma partícula semelhante a vírus designada AaLS [100]. Embora tenham sido observadas proteínas individuais intactas e os respetivos subcomplexos, bem como os iões fragmento, nem todas as subunidades do complexo foram detetadas. Para além disso, foi obtida uma baixa cobertura da sequência da proteína Cas7 ejetada do sistema CRISPR, o que permite a identificação da proteína, mas não permite localizar a presença de modificações.

A captura de iões na frente do espectrómetro de massa (in-source trapping, IST) através do uso de diferentes voltagens foi introduzida recentemente e pode ser usada para uma melhor caracterização dos complexos macromoleculares em instrumentos que contêm apenas um método de ativação e para melhorar a cobertura da sequência de monómeros, permitindo uma melhor identificação das proteínas e localização de modificações. A IST permite a fragmentação dos complexos proteicos na frente do espectrómetro de massa a jusante da fonte de ativação (MS/MS), o que permite fragmentar os monómeros libertados com CID ou UVPD (MS3) $[68,72,101]$. Recentemente a IST foi utilizada para caracterizar sistemas CRISPR [102]. A dissociação do complexo com IST permitiu validar a informação obtida por Cryo-EM e identificar os monómeros que compõem o complexo e a sua massa, como demonstrado na Figura 6.
A

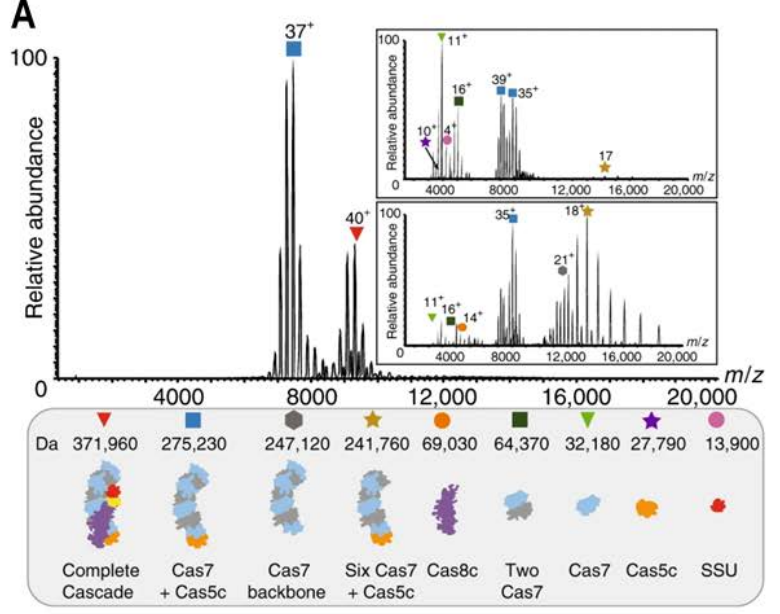

B

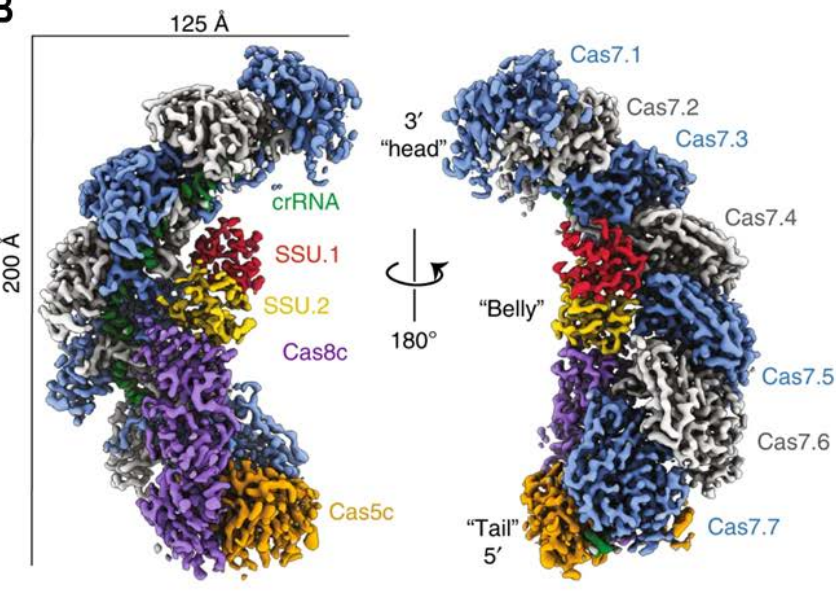

Figura 6 - Operação do tipo I-C e crRNA de Desulfovibrio vulgaris (A). Espectro de massa do complexo CRISPR que confirma a presença de uma subunidade não canónica (B). 0 uso da IST permitiu determinar a composição do complexo e a estequiometria dos monómeros. Os subcomplexos e monómeros identificados estão apresentados por baixo do espectro. Nos insets estão representados os espectros obtidos após IST com voltagens de -120 e -300 V. Estrutura Cryo-EM do complexo com resolução de $3,1 \AA$ (C). As cores na estrutura representam: Cas7, a azul e cinzento; Cas8c, a roxo; Cas5, a laranja; Cas11c, a amarelo e vermelho; crRNA ligado às cinco proteínas, a verde. Adaptada com permissão da referência [102]. 


\subsection{Estudo de ácidos nucleicos}

Embora as proteínas sejam o principal foco da maioria dos estudos na descoberta de novos fármacos, recentemente, uma melhor compreensão da função dos ácidos desoxirribonucleico (ADN), ribonucleico (ARN) e das interações destes com proteínas em muitos processos e patologias suscitou um novo interesse no uso destas moléculas como alvos para o desenvolvimento de fármacos [103-112]. Desta forma, é necessário ter um conhecimento detalhado da sequência, presença de modificações, características estruturais e natureza molecular das interações que modulam as suas funções e interações com outras biomoléculas.

A espectrometria de massa tem sido extensivamente explorada na caracterização de proteínas, quer utilizando métodos de bottom-up ou top-down [113-116]. No entanto, existe ainda uma lacuna no uso da espectrometria de massa para o estudo de ácidos nucleicos, nomeadamente, porque as técnicas tradicionais já permitem sequenciar e quantificar uma grande quantidade de ácidos nucleicos [117]. No entanto, estas técnicas baseiam-se na cópia com base na polimerização do ARN ou do ADN utilizando o emparelhamento da base Watson-Crick, que degenera toda a informação contida nos ácidos nucleicos. Consequentemente, a maioria da informação sobre modificações pós-transcricionais originais é perdida assim que os ácidos nucleicos são copiados, e é aqui que a espectrometria de massa se torna uma técnica analítica complementar [113-116]. A maioria das metodologias para caracterizar ácidos nucleicos focou-se em abordagens de bottom-up que, tal como para as proteínas, utilizam enzimas para digerir ácidos nucleicos em oligonucleótidos mais pequenos e de fácil análise. 0 método de bottom-up é mais simples, mas pode causar a perda de modificações pós-transcricionais que estão relacionadas com a função destas moléculas e com certos tipos de doenças. 0 método de top-downé, portanto, essencial para caracterizar ácidos nucleicos, localizar modificações e identificar locais de interação com outras moléculas. A identificação e caracterização de modificações em ácidos nucleicos, tal como o estudo de complexos entre ácidos nucleicos e ligandos fornecem informações sobre a sua função a nível molecular e aceleraram a descoberta de novos fármacos. Contudo, até à data, esta análise tem sido limitada a ácidos nucleicos com cerca de 10-20 nucleótidos. A análise de ácidos nucleicos com massa superior a 20 kDa é limitada pela presença de adutos. A adição de aditivos tais como sais de amónio voláteis [118], ácidos carboxílicos [119] e bases orgânicas [120,121] é utilizada para reduzir a presença de adutos e simplificar a população de iões produzidos durante o ESI [122].

A espectrometria de massa tandem (MS/MS) permite determinar a sequência dos ácidos nucleicos, identificar a presença de modificações e mapear o local de interação com outras moléculas. Os tipos de iões produzidos após a fragmentação de ácidos nucleicos estão representados na Figura 7. A colisão de ácidos nucleicos com um gás neutro causa fragmentação e produção de iões $a-B$ e $w$ para o $A D N$ e iões c e $y$ para o ARN. Para o ADN, sabe-se que a fraǵmentação é iniciada pela protonação de uma base, gerando um intermediário zwiteriónico, que subsequentemente se dissocia por perda da base e clivagem da ligação 3'-C-O [116]. Em geral, a CID é uma técnica robusta para sequenciar ácidos nucleicos, tal como demonstrado para o tRNA de 25 kDa [123]. Todavia, a perda predominante de bases resulta em fragmentos altamente abundantes que não são informativos para a sequenciação de ácidos nucleicos [116]. Para além disso, a fragimentação por CID de ácidos nucleicos modificados é significativamente menos eficiente e a menor cobertura da sequência dificulta a localização destas modificações $[124,125]$. Recentemente, as técnicas de ativação baseadas em eletrões mostraram resultados promissores na identificação da sequência dos ácidos nucleicos e na retenção de modificações [126-129].

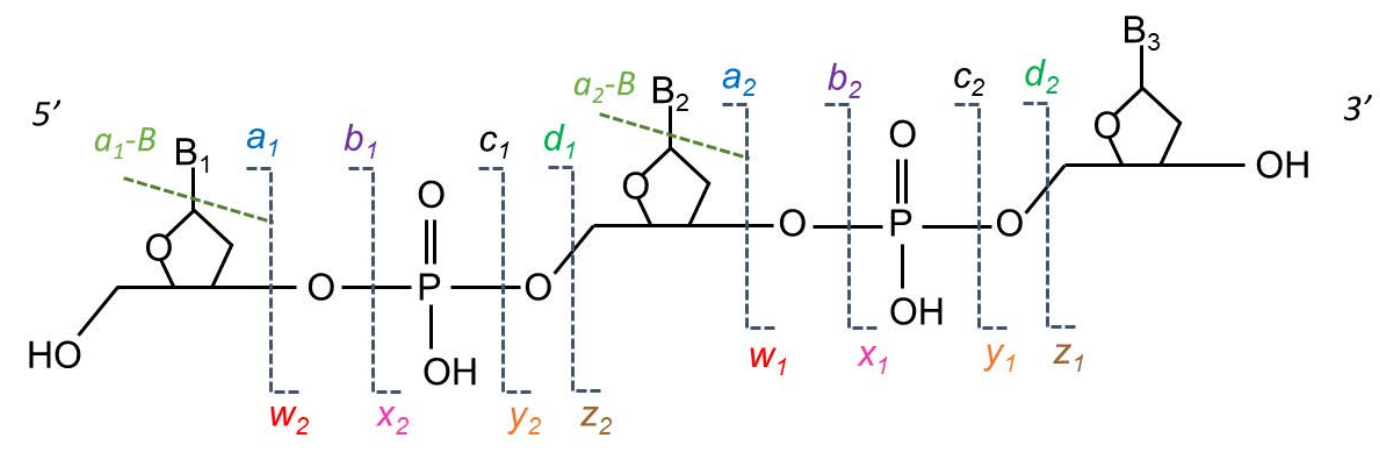

Figura 7 - Tipos de iões formados após ativacão de ácidos nucleicos em espectrometria de massa [116]. 
A

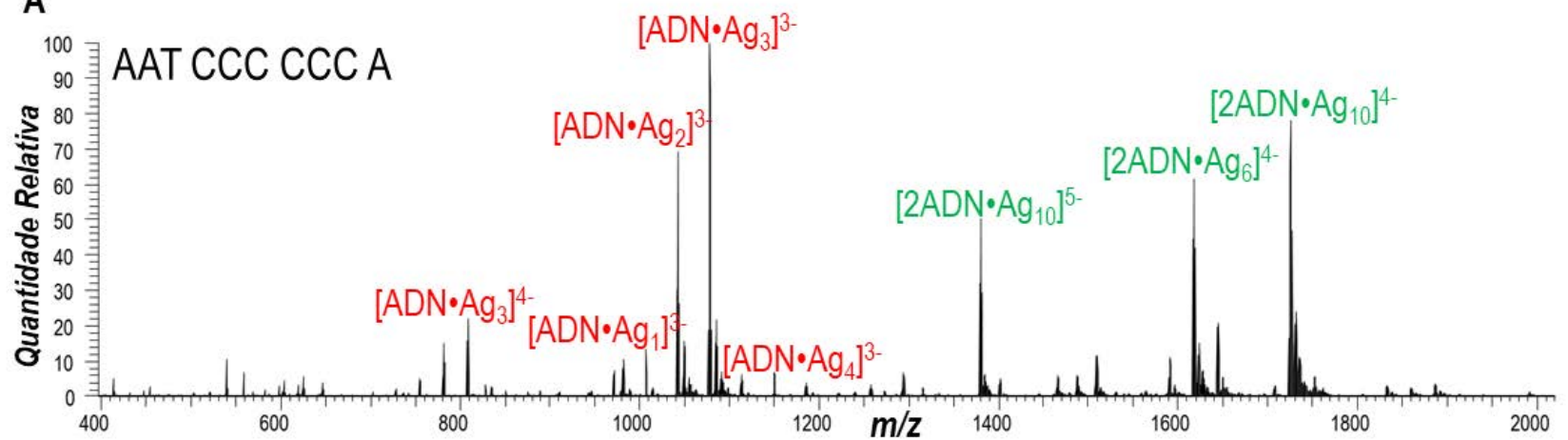

B
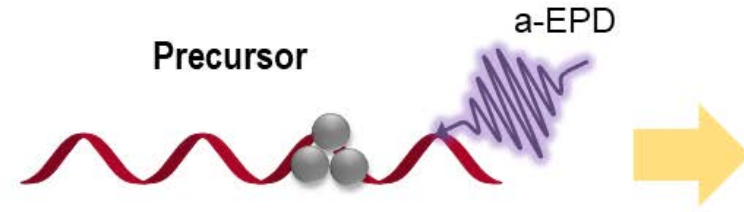

Fragmentos

C

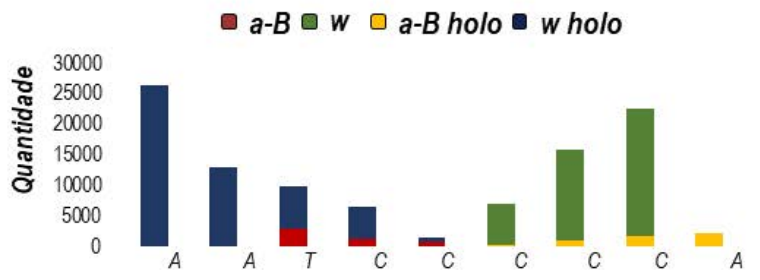

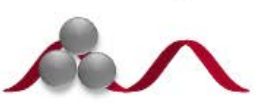

Holo

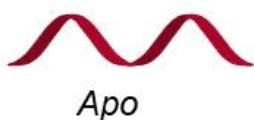

D

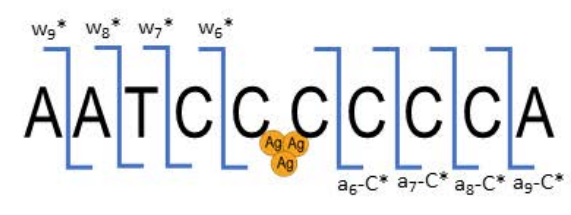

Figura 8 - Espectro de massa de um complexo entre ADN (AATCCCCCCA) e nanopartículas de prata $(A)$. A vermelho estão identificados os complexos com apenas uma cadeia de ADN e a verde estão identificados os complexos com duas cadeias de ADN. Exemplo de fragmentação de $A D N$ : Ag utilizando a-EPD

(B). Abundância de fragmentos produzidos após ativação de ADN com a sequência AATCCCCCCA utilizando a-EPD (C). Cobertura obtida para o fragmento contendo a nanopartícula onde é indicada a localização da interação (D).
Devido à carga negativa destas moléculas, os ácidos nucleicos são mais facilmente detetados em modo negativo. Contudo, a UVPD em modo negativo causa maioritariamente a redução destes iões com baixa produção de fragmentos. De forma a ultrapassar esta limitação, tem sido utilizada a UVPD acoplada com técnicas de ativação baseadas em eletrões (electron transfer, ET) (ET-UVPD) e técnicas de ativação por colisão (CID), denominado activated electron photodetachment (a-EPD) [130-132]. A ET-UVPD de ácidos nucleicos modificados resultou na produção variada de iões $w, a-B, a, b, c, d, x, y$ e $z$ com baixa fragmentação da base em comparação com a CID. Além disso, a ET-UVPD permitiu a deteção de iões de baixa massa ( 1, z1, a1) que facilitaram a caracterização das modificações no término dos ácidos nucleicos [130]. Recentemente, a a-EPD foi utilizada no estudo de ácidos nucleicos complexadas com nanopartículas de prata [131]. Tal como para as proteínas, o uso da UVPD não só produz uma extensa fragmentação dos ácidos nucleicos, como gera fragimentos que mantêm a interação com os ligandos, uma vez que este processo ocorre de forma mais rápida e com maior deposição de energia comparativamente à ativação por CID. Desse modo, são formados fragmentos que contêm o ligando ligado não covalentemente (iões holo) e fragmentos apenas de ácidos nucleicos (iões apo). A perda de cobertura da sequência e a ausência de iões holo indica o local de interação entre os ácidos nucleicos e o ligando como demonstrado para os ácidos nucleicos complexados com nanopartículas de prata na Figura 8. Nesta figura é também possível ver que a partir do espectro de massa se pode determinar o número de átomos de prata que constituem a nanopartícula. Esta estratégia para elucidar os locais de ligação nos complexos de ADN•AgNP foi demonstrada para dois ácidos nucleicos, um com estrutura linear e outro com estrutura hairpin [131]. A a-EPD resultou na produção de vários tipos de fragmentos $(a-B, w, b / y$ e $c / x)$, incluindo muitos que mantiveram a nanopartícula, permitindo assim identificar os locais de ligacção com base nos padrões de fragmentos apo e holo. Esta técnica foi também utilizada para localizar os locais de liģação de iões e ligando a quadruplexos de ADN [132]. 


\section{Conclusões}

A espectrometria de massa tem provado ser uma técnica importante para o estudo de sistemas biológicos, tendo crescido rapidamente. 0 desenvolvimento de diferentes métodos de ativação tem permitido caracterizar proteínas, complexos não covalentes de proteínas com ligando, complexos macromoleculares proteicos, ácidos nucleicos, lípidos, entre outras, e decifrar estruturas tridimensionais, identificar a sequência, locais de interação e a presença de modificações. Uma das estratégías é a utilização de múltiplos modos de ativação e exploração de métodos de ativação híbridos, ambos destinados a aumentar o conteúdo da informação obtida a partir de espectros MS/MS. Um dos desafios atuais encontra-se na implementação de algoritmos de aquisição de dados mais inteligentes e de ferramentas de análise de dados mais avançadas que permitam extrair mais informação dos espectros de massa com o intuito de melhorar a capacidade de estudar estruturas complexas de biomoléculas e a identificação de diferentes modificações presentes em vários resíduos.

\section{Referências}

[1] X. Du, Y. Li, Y.-L. Xia, S.-M. Ai, J. Liang, P. Sang, X.-L. Ji, S. Q. Liu, Int. J. Mol. Sci. 2016, 17, 144. DOI: $10.3390 /$ ijms17020144.

[2] D. C. Fry, Biopolymers 2006, 84, 535-552. DOI: 10.1002/bip.20608.

[3] M. W. Gonzalez, M. G. Kann, PLoS Comput. Biol. 2012, 8, e1002819. DOl: 10.1371/journal.pcbi.1002819.

[4] K. R. Acharya, M. D. Lloyd, Trends Pharmacol. Sci. 2005, 26, 10-14. DOI: 10.1016/j.tips.2004.10.011.

[5] H. Yu, Proc. Natl. Acad. Sci. U. S. A. 1999, 96, 332-334. DOI: 10.1073/ pnas.96.2.332.

[6] H.-W. Wang, J.-W. Wang, Protein Sci. 2017, 26, 32-39. DOI: 10.1002/pro.3022.

[7] M. Carroni, R. Saibil, Methods 2016, 95, 78-85. D0I: 10.1016/j. ymeth.2015.11.023.

[8] E. Callaway, Nature 2015, 525, 172-174. DOI: 10.1038/525172a.

[9] J. A. Loo, Mass Spectrom. Rev. 1997, 16, 1-23. DOI: 10.1002/(SICI)10982787(1997)16:1<1::AID-MAS1>3.0.CO;2-L.

[10] Z. Zhang, S. Wu, D. L. Stenoien, L. P.-Tolic, Ann. Rev. Anal. Chem. 2014, 7, 427-454. DOI: 10.1146/annurev-anchem-071213-020216.

[11] L. C. Gillet, A. Leitner, R. Aebersold, Ann. Rev. Anal. Chem. 2016, 9, 449-472. DOI: 10.1146/annurev-anchem-071015-041535.

[12] L. Konermann, J. Pan, Y-H. Lium, Chem. Rev. 2011, 40, 1224-1234. DOI: 10.1039/COCSO0113A.

[13] K. J. Pacholarz, R. A. Garlish, R. J. Taylor, P. E. Barran, Chem. Soc. Rev. 2012, 41, 4335-4355. DOI: 10.1039/C2CS35035A.

[14] J. D. Eschweiler, R. Kerr, J. R. Gibbons, B. T. Ruotolo, Ann. Rev. Anal. Chem 2017, 10, 25-44. DOI: 10.1146/annurev-anchem-061516-045414.

[15] K. Ishii, M. Noda, S. Uchiyama, Biophys. Physicobiol. 2016, 13, 87-95. 10.2142/biophysico.13.0_87.

[16] M. C. Jecklin, S. Schauer, C. E. Dumelin, R. Zenobi, J. Mol. Recognit. 2009, 22, 319-329. DOl: 10.1002/jmr.951.

[17] E. B. Erba, R. Zenobi, Annu. Rep. Prog. Chem. Sect. C 2011, 107, 199-228. DOl: 10.1039/C1PC90006D.

[18] J. Griffiths. Anal. Chem. 2008, 80, 5678-5683. DOI: 10.1021/ac8013065.

[19] G. D. Christian, P. K. Dasgupta, K. A. Schug, in "Analytical Chemistry", $7^{\text {th }}$ Ed, John Wiley \& Sons, Inc., Hoboken, New Jersey, 2013, pp. 735-766.

[20] A. El-Aneed, A. Cohen, J. Banoub, Appl. Spectrosc. Rev. 2009, 44, 210-230. DOI: $10.1080 / 05704920902717872$

[21] J. B. Fenn, M. Mann, C. K. Meng, S. F. Wong, C. M. Whitehouse, Science 1989 246, 64-71. DOI: $10.1126 /$ science.2675315.

[22] P. Kebarle, L. Tang, Anal. Chem. 1993, 65, 972A-986A. DOI: 10.1021/ ac00070a001.
[23] B. K. Choi, D. M. Hercules, T. Zhang, A. I. Gusev, Curr. Trends in Mass Spectrom. 2003, 18, S24. spectroscopyonline.com/view/comparisonquadrupole-time-flight-and-fourier-transform-mass-analyzers-Ic-msapplications-pdf.

[24] A. M. Haag, "Mass Analyzers and Mass Spectrometers". in: H. Mirzaei, M. Carrasco (eds) "Modern Proteomics - Sample Preparation, Analysis and Practical Applications. Advances in Experimental Medicine and Biology", vol. 919. Springer, Cham. 2016, pp. 157-169. DOI: 10.1007/978-3-319-41448-5_7

[25] L. A. Macias, I. C. Santos, J. S. Brodbelt, Anal. Chem. 2020, 92, 227-251. DOI: 10.1021/acs.analchem.9b04859.

[26] S. A. McLuckey, M. Mentinova, J. Am. Soc. Mass Spectrom. 2011, 22, 3-12. DOI: 10.1021/jasms.8b03888.

[27] J. S. Brodbelt, J. J. Wilson, Mass Spectrom. Rev. 2009, 28, 390-424. DOI: $10.1002 /$ mas.20216.

[28] M. Zhou, V. H. Wysocki, Acc. Chem. Res. 2014, 47, 1010-1018. DOI: 10.1021/ ar400223t.

[29] V. H. Wysocki, K. E. Joyce, C. M. Jones, R. L. Beardsley, J. Am. Soc. Spectrom. 2008, 19, 190-208. DOI: 10.1016/j.jasms.2007.11.005.

[30] K. O. Zhurov, L. Fornelli, M. D. Wodrich, U. A. Laskay, Y. O. Tsybin, Chem. Soc Rev. 2013, 42, 5014-5030. DOI: 10.1039/C3CS35477F.

[31] J. S. Brodbelt, Chem. Soc. Rev. 2014, 43, 2757-2783. DOI: 10.1039/ C3CS60444F.

[32] J. S. Brodbelt, L. J. Morrison, I. Santos, Chem. Rev. 2020, 120, 3328-3380. DOI: 10.1021/acs.chemrev.9b00440.

[33] J. P. Reilly, Mass Spectrom. Rev. 2009, 28, 425-447. DOI: 10.1002/mas.20214.

[34] T. Ly, R. R. Julian, Angew. Chem. Int. Ed. 2009, 48, 7130-7137. D0I: 10.1002/ anie.200900613.

[35] J. S. Brodbelt, J. Am. Soc. Mass Spectrom. 2011, 22, 197-206. DOI: 10.1021/ jasms.8b03957.

[36] T. Baer, R. C. Dunbar, J. Am. Soc. Mass Spectrom. 2010, 21, 681-693. DOI: 10.1016/j.jasms.2010.01.028.

[37] R. Antoine, P. Dugourd, Phys. Chem. Chem. Phys. 2011, 13, 16494-16509. DOI: 10.1039/c1cp21531k.

[38] A. P. Cismesia, L. S. Bailey, M. R. Bell, L. F. Tesler, N. C. Polfer, J. Am. Soc. Mass Spectrom. 2016, 27, 757-766. DOI: 10.1021/jasms.8b05278.

[39] H. J. Zeng, N. Yang, M. A. Johnson, Astrophys. Biol. Faraday Discuss. 2019, 217, 8-33. DOI: 10.1039/C9FD00030E.

[40] C. M. Potel, S. Lemeer, A. J. R. Heck, Anal. Chem. 2019, 91, 126-141. DOI: 10.1021/acs.analchem.8b04746.

[41] N. M. Riley, J. J. Coon, Anal. Chem. 2016, 88, 74-94. DOI: 10.1021/acs. analchem.5b04123. 
[42] Y. Zhang, B. R. Fonslow, B. Shan, M.-C. Baek, J. R. Yates, Chem. Rev. 2013, 113, 2343-2394. DOl: 10.1021/Cr3003533.

[43] J. Mayne, Z. Ning, X. Zhang, A. E. Starr, R. Chen, S. Deeke, C.-K. Chiang, B. Xu, M. Wen, K. Cheng, D. Seebun, A. Star, J. I. Moore, D. Figeys, Anal. Chem. 2016 88, 95-121. DOI: 10.1021/acs.analchem.5b04230.

[44] T. K. Toby, L. Fornelli, N. L. Kelleher, Annu. Rev. Anal. Chem. 2016, 9 , 499-519. DOI: 10.1146/annurev-anchem-071015-041550.

[45] B. Chen, K. A. Brown, Z. Lin, Y. Ge, Anal. Chem. 2018, 90, 110-127. DOI: 10.1021/acs.analchem.7b04747.

[46] J. Eng, A. L. McCormack, J. R. J. Yates, J. Am. Soc. Mass Spectrom. 1994, 5 , 976-989. DOI: 10.1016/1044-0305(94)80016-2.

[47] D. N. Perkins, D. J. Pappin, D. M. Creasy, J. S. Cottrell, Electrophoresis 1999 , 20, 3551-3567. DOI: 10.1002/(sici)1522-2683(19991201)20:18\%3C3551::a id-elps3551\%3E3.0.co;2-2.

[48] J. Cox, M. Mann, Nat. Biotechnol. 2008, 26, 1367-1372. DOI: 10.1038/ nbt.1511.

[49] M. Bern, Y. Kil, J. Proteome Res. 2011, 10, 5296-5301. DOI: 10.1021/ pr200780j.

[50] V. Dorfer, P. Pichler, T. Stranzl, J. Stadlmann, T. Taus, S. Winkler, K. Mechtler, J. Proteome Res. 2014, 13, 3679-3684. DOI: 10.1021\%2Fpr500202e.

[51] A. C. Leney, A. J. Heck, J. Am. Soc. Mass Spectrom. 2017, 28, 5-13. DOI: 10.1021/jasms.8b05378.

[52] S. A. Chandler, J. L. Benesch, Curr. Opin. Chem. Biol. 2018, 42, 130-137. DOl: 10.1016/j.cbpa.2017.11.019.

[53] X. Du, Y. Li, Y.-L. Xia, S.-M. Ai, J. Liang, P. Sang, X.-L. Ji, S. Q. Liu, Int. J. Mol. Sci. 2016, 17, 144. DOI: 10.3390/ijms17020144.

[54] D. C. Fry, Biopolymers 2006, 84, 535-552. DOl: 10.1002/bip.20608.

[55] E. B. Erba, C. Petosa, Protein Sci. 2015, 24, 1176-1192. DOI: 10.1002/pro.2661.

[56] M. Sharon, C. V. Robinson, Annu. Rev. Biochem. 2007, 76, 167-193. DOl: 10.1146/annurev.biochem.76.061005.090816

[57] A. J. R. Heck, Nat. Methods 2008, 5, 927-933. DOl: 10.1038/nmeth.1265.

[58] J. M. Daniel, G. McCombie, S. Wendt, R. Zenobi, J. Am. Soc. Mass Spectrom. 2003, 14, 442-448. DOI: 10.1016/S1044-0305(03)00132-6.

[59] J. P. O'Brien, W. Li, Y. Zhang, J. S. Brodbelt, J. Am. Chem. Soc. 2014, 136, 12920-12928. DOl: 10.1021/ja505217w.

[60] M. Cammarata, J. S. Brodbelt, Chem. Sci. 2015, 6, 1324-1333. DOl: 10.1039/ c4sc03200d.

[61] M. Cammarata, R. Thyer, J. Rosenberg, A. Ellington, J. S. Brodbelt, J. Am. Chem. Soc. 2015, 137, 9128-9135. DOl: 10.1021/jacs.5b04628.

[62] L. J. Morrison, J. S. Brodbelt, J. Am. Chem. Soc. 2016, 138, 10849-10859. DOI: 10.1021/jacs.6b03905.

[63] M. R. Mehaffey, M. B. Cammarata, J. S. Brodbelt, Anal. Chem. 2018, 90, 839846. DOI: 10.1021/acs.analchem.7b03591.

[64] M. Cammarata, C. Shardon, J. Rosenberg, J. Singleton, W. Fast, J. S. Brodbelt, J. Am. Chem. Soc. 2016, 138, 13187-13196. DOI: 10.1021/jacs.6b04474

[65] M. Cammarata, R. Thyer, M. Lombardo, A. Anderson, D. Wright, A. Ellington, J. S. Brodbelt, Chem. Sci. 2017, 8, 4062-4072. DOI: 10.1039/C6SC05235E.

[66] M. R. Mehaffey, C. L. Schardon, E. T. Novelli, M. B. Cammarata, L. J. Webb, W. Fast, J. S. Brodbelt, Chem. Sci. 2019, 10, 8025-8034. DOl: 10.1039/ C9SC01032G.

[67] S. N. Sipe, J. S. Brodbelt, Phys. Chem. Chem. Phys. 2019, 21, 9265-9276. DOI: 10.1039/C9CP01144G.

[68] M. R. Mehaffey, J. D. Sanders, D. D. Holden, C. L. Nilsson, J. S. Brodbelt, Anal. Chem. 2018, 90, 9904-9911. DOI: 10.1021/acs.analchem.8b02099.

[69] I. C. Santos, J. S. Brodbelt, J. Am. Soc. Mass Spectrom. 2021, 32, 1370-1379. DOI: 10.1021/jasms.1c00004.

[70] F. Sobott, H. Hernandez, M. G. McCammon, M. A. Tito, C. V. Robinson, Anal. Chem. 2002, 74, 1402-1407. DOI: 10.1021/ac0110552.

[71] R. H. H. van den Heuvel, E. van Duijn, H. Mazon, S. A. Synowsky, K. Lorenzen, C. Versluis, S. J. J. Brouns, D. Langridge, J. van der Oost, J. Hoyes, A. J. R. Heck, Anal. Chem. 2006, 78, 7473-7483. DOl: 10.1021/ac061039a.

[72] K. L. Fort, M. van de Waterbeemd, D. Boll, M. R.-Szyba, M. E. Belov, E. Sasaki, R. Zschoche, D. Hilvert, A. A. Makarov, A. J. R. Heck, Analyst 2018, 143, 100105. DOI: 10.1039/c7an01629h.

[73] M. A. Tito, K. Tars, K. Valegard, J. Hajdu, C. V. Robinson, J. Am. Chem. Soc. 2000, 122, 3550-3551. DOl: 10.1021/ja993740k

[74] J. Snijder, R. J. Rose, D. Veesler, J. E. Johnson, A. J. R. Heck, Angew. Chem. Int. Ed. 2013, 52, 4020-4023. DOl: 10.1002/anie.201210197.

[75] J. Snijder, A. J. Heck, Annu. Rev. Anal. Chem. 2014, 7, 43-64. Dol: 10.1146/ annurev-anchem-071213-020015.
[76] I. Liko, T. M. Allison, J. T. S. Hopper, C. V. Robinson, Curr. Opin. Struct. Biol. 2016, 40, 136-144. DOI: 10.1016/j.sbi.2016.09.008.

[77] D. S. Chorev, G. B.-Nissan, M. Sharon, Proteomics 2015, 15, 2777-2791. DOI: 10.1002/pmic.201400517.

[78] J. L. P. Benesch, J. A. Aquilina, B. T. Ruotolo, F. Sobott, C. V. Robinson, Chem. Biol. 2006, 13, 597-605. DOl: 10.1016/j.chembiol.2006.04.006.

[79] H. Hernandez, C. V. Robinson, Nat. Protoc. 2007, 2, 715-726. DOl: 10.1038/ nprot.2007.73.

[80] M. G. McCammon, H. Hernández, F. Sobott, C. V. Robinson, J. Am. Chem. Soc. 2004, 126, 5950-51. DOI: 10.1021/ja0317170.

[81] Z. Hall, H. Hernandez, J. A. Marsh, S. A. Teichmann, C. V. Robinson, Structure 2013, 21, 1325-1337. DOI: 10.1016/j.str.2013.06.004.

[82] H. Videler, L. L. Ilag, A. R. McKay, C. L. Hanson, C. V. Robinson, FEBS Lett. 2005, 579, 943-947. DOl: 10.1016/j.febslet.2004.12.003.

[83] C. L. Hanson, P. Fucini, L. L. Ilag, K. H. Nierhaus, C. V. Robinson, J. Biol. Chem. 2003, 278, 1259-1267. DOI: 10.1074/jbc.M208966200.

[84] C. L. Hanson, H. Videler, C. Santos, J. P. Ballesta, C. V. Robinson, J. Biol. Chem 2004, 279, 42750-42757. DOI: 10.1074/jbc.M405718200.

[85] L. L. Ilag, H. Videler, A. R. McKay, F. Sobott, P. Fucini, K. H. Nierhaus, C. V. Robinson, Proc. Natl. Acad. Sci. U.S.A. 2005, 102, 8192-8197. DOI: 10.1073/ pnas.0502193102.

[86] Y. Gordiyenko, H. Videler, M. Zhou, A. R. McKay, P. Fucini, E. Biegel, V. Muller, C. V. Robinson, Mol. Cell Proteomics 2010, 9, 1774-1783. DOl: 10.1074/mcp. M000072-MCP201.

[87] Y. Gordiyenko, S. Deroo, M. Zhou, H. Videler, C. V. Robinson, J. Mol. Biol. 2008, 380, 404-414. DOI: 10.1016/j.jmb.2008.04.067.

[88] L. Wawiórka, D. Krokowski, Y. Gordiyenko, D. Krowarsch, C. V. Robinson, I. Adam, N. Grankowski, M. Tchórzewski, Biochim. Biophys. Acta 2015, 1850 , 150-158. DOI: 10.1016/j.bbagen.2014.10.015.

[89] F. Lermyte, F. Sobott, Proteomics 2015, 15, 2813-2822. D0I: 10.1002/ pmic.201400516.

[90] H. Zhang, W. Cui, J. Wen, R. E. Blankenship, M. L. Gross, Anal. Chem. 2011, 83, 5598-5606. DOI: 10.1021/ac200695d.

[91] H. Li, P. Wongkongkathep, S. L. Van Orden, R. R. O. Loo, J. A. Loo, J. Am. Soc. Mass Spectrom. 2014, 25, 2060-2068. DOI: 10.1007/s13361-014-0928-6.

[92] H. Li, H. H. Nguyen, R. R. O. Loo, I. D. G. Campuzano, J. A. Loo, Nat. Chem. 2018, 10, 139-148. DOI: 10.1038/nchem.2908.

[93] M. Zhou, C. M. Jones, V. H. Wysocki, Anal. Chem. 2013, 85, 8262-8267. DOI: 10.1021/ac401497c

[94] M. Zhou, V. H. Wysocki, Acc. Chem. Res. 2014, 47, 1010-1018. DOl: 10.1021/ ar400223t.

[95] R. S. Quintyn, J. Yan, V. H. Wysocki, Chem. Biol. 2015, 22, 583-592. DOI: 10.1016/i.chembiol.2015.03.019.

[96] Z. L. Van Aernum, J. D. Gilbert, A. M. E. Belov, A. A. Makarov, S. R. Horning, V. H. Wysocki, Anal. Chem. 2019, 91, 3611-3618. DOl: 10.1021/acs. analchem.8b05605.

[97] S. Vimer, G. B. Nissan, D. Morgenstern, F. K.-Deshmukh, C. Polkinghorn, R. S. Quintyn, Y. V. Vasil'ev, J. S. Beckman, N. Elad, V. Wysocki, M. Sharon, ACS Cent. Sci. 2020, 6, 573-588. DOI: 10.1021/acscentsci.0c00080.

[98] S. N. Sipe, J. W. Patrick, A. Laganowsky, J. S. Brodbelt, Anal. Chem. 2020 , 92, 899-907. DOI: 10.1021/acs.analchem.9b03689.

[99] S. Tamara, A. Dyachenko, K. L. Fort, A. A. Makarov, A. Scheltema, A. J. R. Heck, J. Am. Chem. Soc. 2016, 138, 10860-10868. DOI: 10.1021/jacs.6b05147

[100] J.-F. Greisch, S. Tamara, R. A. Scheltema, H. W. R. Maxwell, R. D. Fagerlund, P. C. Fineran, S. Tetter, D. Hilvertd, A. J. R. Heck, Chem. Sci. 2019, 10, 7163-7171. DOI: 10.1039/c9sc01857c.

[101] M. E. Belov, E. Damoc, E. Denisov, P. D. Compton, S. Horning, A. A. Makarov, N. L. Kelleher, Anal. Chem. 2013, 85, 11163-11173. DOI: 10.1021/ac4029328.

[102] R. E. O'Brien, I. C. Santos, D. Wrapp, J. P. K. Bravo, E. A. Schwartz, J. S. Brodbelt, D. W. Taylor, Nat. Commun. 2020, 11, 5931. DOI: 10.1038/541467020-19785-8.

[103] K. Sridharan, N. J. Gogtay, Br. J. Clin. Pharmacol. 2016, 82, 659-672. DOI 10.1111/bcp.12987.

[104] A. Huttenhofer, P. Schattner, N. Polacek, Trends Genet. 2005, 21, 289-297. DOI: 10.1016/j.tig.2005.03.007.

[105] A. Huttenhofer, J. Brosius, J. P. Bachellerie, Curr. Opin. Chem. Biol. 2002, 6 , 835-843. DOI: 10.1016/S1367-5931(02)00397-6.

[106] J. S. Mattick, Nat. Rev. Genet. 2004, 5, 316-323. DOI: 10.1038/nrg1321.

[107] C. J. T. Lewis, T. Pan, A. Kalsotra, Nature Rev. 2017, 18, 202-210. DOI: 10.1038/nrm.2016.163. 
[108] M. Matsui, D. R. Corey, Nat. Rev. Drug Discov. 2017, 16, 167-179. DOI: 10.1038/nrd.2016.117.

[109] E. Lekka, J. Hall, FEBS Lett. 2018, 592, 2884-2900. DOI: 10.1002/18733468.13182.

[110] K. M. Weeks, Curr. Opin. Struct. Biol. 2010, 20, 295-304. DOI: 10.1016/j. sbi.2010.04.001.

[111] L. E. Rieder, C. J. Staber, B. Hoopengardner, R. A. Reenan, Nat. Commun. 2013, 4, 2232. DOI: 10.1038/ncomms3232.

[112] M. Kaushik, S. Kaushik, K. Roy, A. Singh, S. Mahendru, M. Kumar, S. Chaudhary, S. Ahmed, S. Kukreti, Biochem. Biophys. Rep. 2016, 5, 388-395. DOI: 10.1016/j.bbrep.2016.01.013.

[113] P. A. Limbach, P. F. Crain, J. A. McCloskey, Curr. Opin. Biotechnol. 1995, 6, 96-102. DOI: 10.1016/0958-1669(95)80015-8.

[114] J. H. Banoub, R. P. Newton, E. Esmans, D. F. Ewing, G. Mackenzie, Chem. Rev. 2005, 105, 1869-1915. DOI: 10.1021/cr030040w.

[115] D. Fabris, J. Am. Soc. Mass Spectrom. 2010, 21, 1-13. DOI: 10.1016/j. jasms.2009.09.006.

[116] S. Schurch, Mass Spectrom. Rev. 2016, 35, 483-523. DOI: 10.1002/ mas.21442.

[117] J. Shendure, H. L. Ji, Nat. Biotechnol. 2008, 26, 1135-1145. DOI: 10.1038/ nbt1486.

[118] R. H. Griffey, H. Sasmor, M. J. Greig, J. Am. Soc. Mass Spectrom. 1997, 8, $155-$ 160. DOI: 10.1016/S1044-0305(96)00200-0.

[119] M. Taucher, U. Rieder, K. Breuker, J. Am. Soc. Mass Spectrom. 2010, 21, 278285. DOI: 10.1016/j.jasms.2009.10.010.

[120] M. Greig, R. H. Griffey, Rapid Commun. Mass Spectrom. 1995, 9, 97-102. DOI: $10.1002 / \mathrm{rcm} .1290090121$

[121] B. Ganisl, M. Taucher, C. Riml, K. Breuker, Eur. J. Mass Spectrom. 2011, 17, 333-343. DOI: 10.1255/ejms.1140.
[122] K. Breuker, "Characterization of Ribonucleic Acids and Their Modifications by Fourier Transform Ion Cyclotron Resonance Mass Spectrometry". in Gabelica V. (eds) "Nucleic Acids in the Gas Phase. Physical Chemistry in Action". Springer, Berlin, Heidelberg, 2014. pp. 185-202. D0I: 10.1007/9783-642-54842-0_7.

[123] T. Y. Huang, J. A. Liu, S. A. McLuckey, J. Am. Soc. Mass Spectrom. 2010, 21, 890-898. DOI: 10.1016/j.jasms.2009.12.007.

[124] Y. Gao, S. A. McLuckey, J. Mass Spectrom. 2012, 47, 364-369. D0I: 10.1002/ jms.2044.

[125] T.-Y. Huang, A. Kharlamova, S. A. McLuckey, J. Am. Soc. Mass Spectrom. 2010, 21, 144-153. DOI: 10.1016/j.jasms.2009.09.020.

[126] T. M. P.-Clarke, Q. Quan, D. R. Brademan, A. S. Hebert, M. S. Westphall, J. J. Coon, Anal. Chem. 2020, 92, 4436-4444. DOI: 10.1021/acs. analchem.9b05388.

[127] M. Taucher, K. Breuker, Angew. Chem. Int. Ed. 2012, 51, 11289-11292. DOI: 10.1002/anie.201206232.

[128] G. Calderisi, H. Glasner, K. Breuker, Angew. Chem. Int. Ed. 2020, 59, 43094313. DOI: 10.1002/anie.201914275.

[129] S. I. Smith, J. S. Brodbelt, Anal. Chem. 2010, 82, 7218-7226. DOI: 10.1021/ ac100989q.

[130] S. I. Smith, J. S. Brodbelt, Anal. Chem. 2011, 83, 303-310. DOI: 10.1021/ ac102411a.

[131] M. S. Blevins, D. Kim, C. M. Crittenden, S. Hong, H.-C. Yeh, J. T. Petty, J. S. Brodbelt, ACS Nano 2019, 13, 14070-14079. DOI: 10.1021/ acsnano.9b06470.

[132] D. Paul, A. M. D. Verga, S. Bombard, M. P. T.-Fichou, F. Rosu, V. Gabelica, Analyst 2019, 144, 3518-3524. DOI: 10.1039/C9AN00398C.

\section{Inês C. Santos}

Department of Chemistry, University of Texas at Austin, Austin, U.S.A.

Oncology R\&D, AstraZeneca R\&D, Waltham, MA 02451, U.S.A. (afiliação atual).

Inês C. Santos é Research Scientist na AstraZeneca, Waltham, U.S.A. Obteve o seu Doutoramento na Universidade

Católica Portuguesa. Durante o seu pós-doutoramento no laboratório da Professora Jennifer Brodbelt na Universidade do Texas em Austin, a sua investigação centrou-se no uso de espectrometria de massa acoplada à fotodissociação ultravioleta para caracterizar moléculas biológicas.

ines.santos@astrazeneca.com ORCID.org/0000-0002-4609-7085 